\title{
Global Health: Issues and Challenges
}

Shinu KURIAKOSE ${ }^{1}$

\begin{abstract}
The challenges facing global health continue to evolve and will very soon emerge as an emergent problem due to the various conditions which fuel this issues. The combination of increased population, ageing which is more focused currently on quantity versus quality of life, chronic hunger issues, lack of clean drinking water puts a combined pressure on the resources we possess to a breaking point. It is imperative that developed countries with the assistance of non-governmental organizations take the lead in educating underdeveloped countries and entities into initiating sustainable practices, which will help, control the various challenges for global health with a long-term view of eliminating these obstacles. There needs to be investments made in harvesting clean water, implementing sustainable farming practicing, providing micro-loans to access funds and an improved focus on birth control practices. As the population continues to grow, access to resources will continue to be limited and only available to the rich and wealthy; a scenario, which will only lead to, increased potential of global calamity.
\end{abstract}

\section{INTRODUCTION}

The world is increasingly more interconnected due to various advances in technology, transportation, electronic communication modalities, and common interests. In this landscape, global health issues bears a thorough look as diseases can travel at an exponential pace compared to just a generation ago. The technology, which makes our life easier, also has a darker side when it also enables bacteria and viruses to infect people on opposite side of the globe without fair warning. It is increasing incumbent on all of us including governments, nongovernmental organizations (NGO's), private health care sectors, pharmaceutical companies and research and developmental entities to be aware that a small outbreak of illness can be transmitted globally and become a pandemic if not appropriately mitigated. "Greater movement of people and of products - including foods, feed, drugs, and medical devices - can increase exposure to potential health risks originating outside the United States"(GlobalHealth.gov, 2015).

On the positive side of this issue is the likelihood of effective vaccines and cures being made available in a short time to folks all over the world if successful in a given area. It is prudent the United States Government (US) has tasked the Department of Health and Human Services (HHS) to take the lead into tackling the myriad of challenges facing global healthcare in these times. The US has articulated their opinion in the Global Health Strategy (GHS) policy paper for the time period form 2011-2015, which emphasizes the need for collaboration across many countries and private agencies to help address health care disparities and public health concerns (GlobalHealth.gov, 2015). The GHS policy attempts to address multiple issues including utilizing evidence based research, collaboration among interested parties, conducting needs assessments, eva-

\section{Corresponding author.}

Shinu KURIAKOSE DHSc, PA-C, School of Health Professions, New York Institute of Technology, Riland Building, Room 35, Old Westbury Campus, USA.

E-mail: skuria06@nyit.edu 
luating local capacities and impacts, and most importantly prevention strategies.

\section{DISCUSSION}

\section{Aging population}

One of the fundamental challenges facing healthcare globally is the growing population and ever dwindling resources. Countries like China (population 1.349.585.838) and India (population 1,220,800,359) are increasingly using their scarce resources to help satisfy the needs of their citizens; however, the increased ageing of their population coupled with sickness and disability is putting a huge strain both financially and socially in these countries (HJF Foundation, 2015). As the population continues to grow older due to the advancements made in medicines and screening techniques, noncommunicable diseases such as heart disease, diabetes, and hypertension are increasingly being seen in the elderly population. Copious amounts of monies are spent in treating patients with these conditions with a increased focus on how long life can be prolonged rather than the quality of life. The Global Health Education Consortium (GHEC) has projected that there are one million more births than deaths that occur every 110 hours (GHEC, 2015). It further states that although it took humans 300.000 years to reach one billion in number, the last 12 years have seen an increase of almost two billion people (GHEC, 2015). This exponential growth is not sustainable in the long term due to the limitation of resources on earth. It has also been noted that this impact can affect educational goals of society as children in large households have less primary and secondary education while the need for teachers to teach this increased cohort is dire. Furthermore, there is a correlation noted between increased fertility in women and high child mortality per the GHEC. Additionally, research has show that reducing unintended pregnancies would be beneficial to the mother's health and reduce maternal deaths (Daulaire, 2002).

A report by the UK Parliament hearings has projected an increased water shortage as the population grows: Population of 6 billion (currently) reveals a $92 \%$ water sufficiency in the population with a relatively low $3 \%$ scarcity, while a population increase to 8 billion in 2025 may lead to a water sufficiency of $62 \%$ with a scarcity as high as $8 \%$ (UK Parliament, 2007). Another fact, which can influence global health, is over farming in areas with limited water supply; a process, which could lead to limited agricultural resources and increased pressure, put on alternate food resources such as animal meat and fishing (UK Parliament, 2007). The GHEC in its report focuses on the impact population can have on the economy of a country. It states that in developing countries with lower fertility, there is an increase between 25-40 percent in the economy, which is directly attributable to the demographic change. An example of this is seen in Asia where lower birthrates have led to economic growth while in parts of Africa with higher fertility there is reduced economic growth with increased poverty (GHEC, 2015).

\section{Public health}

The Centers for Disease Control (CDC) has renewed its emphasis on global health security as a means of protecting and enhancing global health programs such as vaccinations, flu prevention, maternal and child health, screening for contagious diseases. It does so by focusing on some key areas which enhance security such as „build better lab systems; create faster and more accurate data sharing; establish and improve emergency operations centers that can respond more quickly to all public health crises; and support nationwide surveillance systems that enable real-time disease tracking and reporting" (CDC, 2014).

There is increased recognition by the CDC, which it attempts to impart to other national, international, and foreign health care entities, about the speed at which infections can spread across different regions due to the advances in transportation, the need to have greater scrutiny on the transport of food, medical equipment including medicines and the increasing incidence of drug resistance. It also encourages vaccinations of citizens by their host countries, which would help citizens of the world, be safer due to less transmission of diseases and protective herd immunity.

\section{Economical health}

Poor health systems and increased incidence of disease in a population can lead to inadvertent economic sanctions indirectly. The $\mathrm{CDC}$ has tried to enlighten other nations that there would be fewer tourists travelling to a country where poor hygiene or other medical conditions has led to folks getting ill, there would be less trade delegations looking to conduct business in these areas and any kind of pandemic would be devastating to the economy of these countries. Another dire concern, which will affect economies of a country, is the 
impending water shortage issue; a problem, which is growing worse due to increased global warming and wastage of drinking water by poor infrastructure. The access to clean water has shown improvement in school attendance by freeing up students who otherwise would spend their time gathering water in areas of Afri$\mathrm{ca}$, allowing girls to be in class if latrine facilities are available, reduced hunger in the population as access to water can help with farming and growing crops to feed citizens of the country, and finally, clean water can help with hygienic purposes which leads to less morbidity and mortality in the population (The Water Project, 2015).

Hunger continues to be a problem in the developing world, which leads to increased illness and disability affecting the economic health of countries. It is estimated that out of the 805 million people suffering from hunger, over 98\% lives in the developing world (The Hunger Project, 2015). The Hunger Project is an initiative, which seeks to make citizens of sub-Saharan Africa, Latin America and parts of Asia to employ sustainable methods to be self-reliant and employ techniques to grow and stock excess food to be used in times of need. This project recognizes that policies like financing farmers in a microfinance model and promoting sustainable agricultural activities will help mitigate this growing epidemic of hunger, which has global implications.

\section{References}

1. GlobalHealth.gov (2015). Global Health Strategy. Retrieved from http://www.globalhealth.gov/global-programs-and-initiatives/ global-healthstrategy/index.html

2. Henry J. Kaiser Foundation (2015). Population Growth Facts. Retrieved from http://kff.org/global-indicator/populationgrowth-rate/

3. Xue-Qiang, W and Pei-Jie, C (2014, March 8). Population Ageing Challenges Health Care in China. The Lancet. 383 (9920), p870. Retrieved from http://www.thelancet.com/journals/lancet/article/PIIS0140-6736\%2814\%2960443-8/fulltext

4. Daulaire N. Promises to Keep: The Toll of Unintended Pregnancies on Women's Lives in the Developing World. Global health Council, 2002.

\section{RECCOMMENDATIONS}

I strongly believe that it will take a combination of individual will and institutional (government or private) funding to tackle the growing problems which affect global health. Folks who might see starvation or lack of resources during the evening news in a far off country may not appreciate the magnitude of this problem and the ease, which this issue can spread and affect them. There has to be renewed emphasis on birth control techniques with increased sustainable practices which ensure that everybody in the world has their basic needs met. Entrepreneurs who develop techniques or initiate projects, which may cause a dent in the challenge of global health, should be offered tax incentives to help them see their projects fulfilled. It behooves us all to recognize that we are all together in this small blue earth and the decisions we make in making our planet safer will be beneficial to not only us at the present time but also future generations to come.

Compliance with ethics requirements: The authors declare no conflict of interest regarding this article. The authors declare that all the procedures and experiments of this study respect the ethical standards in the Helsinki Declaration of 1975, as revised in 2008(5), as well as the national law. Informed consent was obtained from all the patients included in the study.

5. Return of the Population Growth Factor: The Impact on the Millennium Development Goals. Report of the UK Parliament hearings, London 2007

6. Centers for Disease Control and Prevention (2014). Why Global Health Security Matters. Retrieved from http://www.cdc.gov/ globalhealth/security/why.htm

7. The Water Project (2015). Why Water: Dirty water causes needles suffering. Retrieved from http://thewaterproject.org/whywater

8. The Hunger Project (2015). Hunger. Retrieved from http://thp. org/issues/hunger/

9. Global Health Workforce Alliance (2015). Global Health Education Consortium. Retrieved from http://www.who.int/workforcealliance/members_partners/member_list/ghec/en/ 
